\title{
Política de Avaliação da Educação Brasileira: limites e perspectivas
}

\author{
Evaluation Policy of Brazilian Education: limits and perspectives \\ Política de Evaluación de la Educación Brasileña: límites y perspectivas
}

\section{Maria Angélica Pedra Minhoto1}

\section{Resumo}

Este artigo trata da constituição e funcionamento do Sistema Nacional de Avaliação da Educação brasileira. O texto recupera informações importantes sobre a origem deste sistema, bem como apresenta e discute as características das peças que o compõem. Analisando os objetivos declarados pelo sistema e os problemas na sua implementação, o trabalho conclui mostrando sua insuficiência e a necessidade de constituição de uma avaliação rigorosa da qualidade das escolas e dos sistemas educacionais, como elemento imprescindível para a construção de uma sociedade justa e democrática.

Palavras-chave: Sistema Nacional de Avaliação; Educação Básica; Avaliação Educacional.

\begin{abstract}
This article deals with the constitution and functioning of the Evaluation National System in Brazilian Education. The text retrieves important information about the origin of this system, as well as presents and discusses its characteristics. Analyzing the declared objectives of the system and the problems in its implementation, the study concludes showing its insufficiency and the need to establish a rigorous evaluation of the quality of schools and educational systems, as an essential element for the construction of a just and democratic society.
\end{abstract}

Keywords: Evaluation National System; Basic Education; Education Assessment.

\section{Resumen}

Este artículo trata del establecimiento y funcionamiento del Sistema Nacional de Evaluación de la educación brasileña. El texto recupera informaciónes importantes acerca del origen de este sistema y presenta y discute las características de las piezas que lo componen. El trabajo hace el análisis de los objetivos establecidos por el sistema y los problemas en su implementación, y concluye muestrando su fracaso y la necesidad de establecer una evaluación rigurosa de la calidad de las escuelas y los sistemas educativos, como un elemento esencial para la construcción de una sociedad justa y democrática.

Palabras-clave: Sistema Nacional de Evaluación; Educación Básica; Evaluación Educativa. 


\section{Introdução}

Após a promulgação da atual Constituição Federal (CF), em 1988, o Ensino Fundamental (EF) foi instituído como direito público subjetivo dos brasileiros, uma etapa obrigatória a ser oferecida regular e gratuitamente pelo Estado. Em 11/11/2009, foi promulgada a Emenda Constitucional n 59 que além de prever a gradual extinção do percentual da Desvinculação das Receitas da União (DRU), ampliou a obrigatoriedade do ensino para a faixa etária que vai de 4 a 17 anos, medida a ser implementada progressivamente até 2016. Em decorrência, tanto pais ou responsáveis pelas crianças e jovens, quanto administrações públicas, ficarão obrigados a garantir o acesso e a permanência dessa população na escola, podendo ser inclusive responsabilizados judicialmente pelo descumprimento de suas obrigações. Além disso, a CF estabelece como princípio a garantia de um padrão de qualidade, não apenas para o ensino obrigatório, mas para toda a educação brasileira.

Como desdobramento da carta maior, a Lei de Diretrizes e Bases da Educação Nacional (LDB - Lei $n^{\circ}$ 9394/96, de 24/12/96), em seu art. 9 , oficializou procedimentos de avaliação externa com o objetivo de induzir e cobrar dos sistemas de ensino o referido padrão de qualidade. À União ficou determinado que assegurasse um "processo nacional de avaliação do rendimento escolar no ensino fundamental, médio e superior, em colaboração com os sistemas de ensino, objetivando a definição de prioridades e a melhoria da qualidade do ensino". Com isso, as décadas que se seguiram após a promulgação da Lei vêm se mostrando ricas em diversas e sistemáticas iniciativas de avaliação em larga escala, em todas as etapas da educação formal, reafirmando as competências de regulação e supervisão da União no que diz respeito aos sistemas educacionais.

Organizados em âmbito federal, pode-se observar procedimentos como a Provinha Brasil (2007); a Avaliação Nacional da Alfabetização - ANA (2013); a Prova Brasil, a ANEB (2005) e o SAEB (1990); o ENEM (1998); o ENCCEJA (2002); o PAIUB (1993), o ENC-Provão (1996 a 2003) e o SINAES-ENADE (2004); para além daavaliação da pós-graduação, que já vinha ocorrendo desde 1976. Esse movimento é seguido, também, em âmbito estadual, quase todas as unidades da federação têm organizado ou já organizaram avaliações externas de seus sistemas de ensino e é possível constatar que um crescente número de municípios vem também aderindo à iniciativa.

A instituição desses processos pode ser caracterizada basicamente por exercer duas funções distintas: 1) levantar informações ou evidências necessárias à formulação de políticas educacionais, tendo como propósito ampliar e aprofundar o conhecimento sobre os sistemas de ensino para que as diferentes esferas de governo possam definir prioridades de intervenção; e 2) induzir mudanças ou consolidar reformas educacionais previamente estruturadas para os sistemas de ensino.

Sem a intenção de esgotar assunto tão amplo e complexo, este texto traça um breve panorama histórico das iniciativas de avaliação externa na Educação Básica, introduzidas pela União a partir da década de 1990, pontuando suas características, trajetórias, diferentes desdobramentos e pontos críticos, além de procurar tornar explícitas as lógicas aí subjacentes.

Antes, porém, faz-se necessária uma distinção conceitual acerca do termo "avaliação", fundamental para compreender a política de avaliação da educação. Tomada a definição do termo, no dicionário Houaiss notase que "avaliação" figura com os seguintes significados: 1) cálculo do valor de um bem ou de bens; 2) valor determinado por aquele que avalia; 3) apreciação ou conjectura sobre condições, extensão, intensidade, qualidade de algo; 4) verificação que objetiva determinar a competência e o progresso de um profissional, de um aluno, etc. Com tais características, a avaliação se relaciona intrinsecamente à aferição (de valor, de condições, de intensidade, de qualidade, de competência, etc.). Entretanto, haveria diferença entre avaliar e aferir, no caso da política educacional? Em caso positivo, como se poderia então conceituar essa diferença?

A aferição e a avaliação também estão intimamente relacionadas, no caso das avaliações em larga escala, no entanto devem ser diferenciadas. A primeira se propõe a mensurar um construto, ou em outros termos, a versão operacionalizada de um conceito. Por exemplo, pode-se construir, a partir de algumas variáveis, diferentes 
escalas para medir conceitos como os de inteligência, competência, preconceito, nível socioeconômico, etc. Pesquisadores procedem dessa maneira pela impossibilidade de capturar diretamente da realidade a inteligência, a competência, o preconceito, o nível socioeconômico, etc., devido ao caráter abstrato que apresentam.

Muitas pesquisas caminham em direção à definição, redefinição e atualização desses e de muitos outros conceitos e de suas manifestações sociais. Por aferição pode-se entender, portanto, a mensuração de variáveis que compõem a definição de um conceito. Exemplificando: para se medir e classificar o nível socioeconômico de uma pessoa (ou grupo de pessoas), levantam-se dados tais como: a posse de bens e sua quantidade (televisores, computadores, eletrodomésticos, automóveis, imóveis etc.), o nível de escolaridade/instrução da família (ou chefe da família), a profissão desempenhada pelo sujeito, o emprego exercido, a situação funcional, o ganho bruto/líquido mensal, a jornada de trabalho etc. Juntas, essas informações compõem um quadro explicativo que pretende sintetizar a relação entre o conceito teórico e os dados encontrados na empiria.

Já a avaliação pode ser definida comoa complexa trama de relações estabelecidas entre diferentes construtos. Nesse sentido, as provas e testes que aferem a proficiência dos estudantes só se transformam de fato em avaliação educacional quando os seus resultados são relacionados a outros construtos, como, por exemplo, as características socioeconômicas dos alunos; as experiências escolares; as motivações para o curso; o ambiente educacional; as condições de infraestrutura da instituição de ensino, entre outros.

Ainda que limitada, a avaliação vista dessa maneira permite a realização de uma leitura mais refinada dos resultados de processos avaliativos em larga escala, o que pode (e deve) evitar o potencial já bem conhecido que têm para legitimar diferenças sociais convertendo-as em diferenças escolares. Apesar disso, não se pode deixar de destacar que a conversão dos conceitos em constructos, a elaboração de correlações entre os construtos e a construção de indicadores educacionais, a partir de informações levantadas nos processos avaliativos, são procedimentos formais e subjetivos de seleção e de construção da "realidade". Tais procedimentos referem-se a seleções previamente realizadas, são apenas um ângulo, selecionado pelo observador, um ponto de vista do pedaço de realidade que será dado a ver. Além disso, a informação obtida geralmente está subordinada ao próprio método de levantamento de dados. Assim, a forma de aproximação e codificação das informações que serão operadas estatisticamente apresenta tanto uma conceituação do fenômeno que pretende capturar quanto um padrão a ser seguido (BESSON, 1995).

Nesse sentido, a imagem da realidade instituída pelos indicadores educacionais deve ser entendida como fruto de uma construção social que tem por finalidade representar o mundo sob o ponto de vista de seu produtor. Quando se acredita na neutralidade e veracidade de tais índices, porque supostamente os técnicos que os produzem seriam tão somente operadores racionais de dados da realidade, a imagem resultante tem grande probabilidade de ser percebida como fato, e assim, sua intencionalidade é descartada. Entretanto, vale reiterar o alerta: há que se ter presente todo o tempo que tal imagem não é fato, mas uma construção cheia de intencionalidade. Do contrário, a confusão poderá promover a falsa compreensão da imagem, que provavelmente será tomada como o real.

\section{As Políticas de Avaliação da Educação Básica}

\section{SAEB/ANEB, Prova Brasil e ANA}

Desde 1988, é possível acompanhar o desenvolvimento de um sistema que se propõe a avaliar e monitorar a qualidade da educação básica, no país, chamado Sistema Nacional de Avaliação da Educação Básica (SAEB). Além de objetivar tal diagnóstico, o sistema foi concebido para auxiliar a formulação de políticas educacionais pelas administrações públicas. Até o ano de 2015, já foram conduzidas 13 edições do exame, sendo a próxima programada para 2017. 
Desde o início, o SAEB buscou relacionar o resultado do desempenho obtido pelos estudantes matriculados nos finais de ciclos da educação básica (Ensino Fundamental l e ll e Ensino Médio) em testes padronizados, nas disciplinas de Matemática e Língua Portuguesa, com possíveis fatores que lhe fossem associados. Para tanto, além do teste de múltipla escolha, o SAEB coleta informações sobre os hábitos de estudo dos alunos, suas condições socioeconômicas, as características das turmas, as condições socioeconômicas dos professores e diretores, bem como as condições de infraestrutura das escolas.

O desenho do SAEB é similar ao de várias avaliações estruturadas em países centrais. São procedimentos que foram modelados a partir de diferentes tipos de pesquisas, como os grandes surveys educacionais - 0 Relatório Coleman, nos EUA, e o Relatório Plowden, na Inglaterra, que buscaram compreender a relação entre o desempenho escolar e fatores externos à escola - e pesquisas que atentaram para o impacto dos fatores propriamente escolares no desempenho dos estudantes (BONAMINO; FRANCO, 1999).

Ao longo de sua existência, o SAEB passou por importantes mudanças metodológicas. Aperfeiçoou tanto os instrumentos de coleta de informações contextuais - os questionários dos alunos, professores, diretores, da escola e das turmas, como a própria elaboração dos testes de proficiência dos alunos - com a produção de matrizes curriculares de referência para subsidiar a construção dos itens de múltipla escolha e aadoção da Teoria de Resposta ao Item (TRI), que permitiu comparar o desempenho dos alunos, ao longo dos anos, e entre as séries, além de apresentar maior potencial de discriminação do nível de proficiência de cada aluno.

A cobertura do exame também se ampliou. A partir de 1995, o SAEB alcançou cobertura nacional, com a participação das 27 unidades da federação e, em algumas edições, incluiu a rede particular em sua amostra. Em 2005, o Ministério da Educação (MEC) dividiu o SAEB em dois instrumentos distintos: a Avaliação Nacional dos Estudantes da Educação Básica (ANEB) e a Prova Brasil. O objetivo do primeiro instrumento, que continua sendo chamado de SAEB, é o de divulgar resultados da qualidade da educação de forma agregada - por regiões, unidades da federação ou redes de ensino (pública ou particular) - e não por escolas isoladamente. Por isso, é um levantamento amostral que incide em estratos predefinidos da população. Já a Prova Brasil tem âmbito universal, no que se refere às redes de escolas públicas urbanas e rurais que tenham mais de 20 alunos matriculados no ano/série a ser avaliado e fornece resultados do desempenho por município e por escola, individualmente. Seu objetivo, de acordo com o MEC, é o de auxiliar a formulação de políticas educacionais e de direcionar recursos técnicos e financeiros dos governos.

Segundo Fernandes e Gremaud (2009), a divisão do SAEB foi necessária para responder às demandas do processo de descentralização e municipalização do EF, ocorrido sistematicamente a partir da instituição do Fundo de Manutenção e Desenvolvimento do Ensino Fundamental e de Valorização do Magistério (Fundef), em 1997. A diversidade das formas de gestão e da elaboração de políticas educacionais passou a exigir uma avaliação censitária, para que fosse possível a auto-avaliação dos municípios, segundo os autores. Em 2005, a Prova Brasil e o SAEB fizeram uso de instrumentos diferentes de avaliação, diversamente do que ocorreu a partir de 2007, que passaram a utilizar os mesmos instrumentos, tendo tido a Prova Brasil, portanto, característica de um SAEB com estratos censitários.

Ao longo dos anos, o papel dessas avaliações externasse expandiu. Além de diagnosticar os problemas e monitorar o desempenho dos sistemas de ensino, esses procedimentos vêm ocupando lugar de destaque na definição dos rumos das políticas do MEC e interferindo nos processos de ensino aprendizagem no interior das escolas. Em março de 2007, o Presidente Lula e o então ministro da educação, Fernando Haddad, apresentaram o Plano de Desenvolvimento da Educação (PDE), contendo 30 metas e ações com o intuito de melhorar a qualidade do ensino no país. Para monitorar as ações e metas do plano foi instituído um indicador chamado Índice de Desenvolvimento da Educação Básica (IDEB), composto por outros dois indicadores: a taxa média de aprovação, captada pelo Censo Escolar, e a pontuação média obtida na Prova Brasil.O cálculo do IDEB é o produto entre o desempenho e o rendimento escolar, varia de 0 a 10 e é desdobrável por Estados, municípios, redes de ensino e escolas. 
A intenção da União é a de que o IDEB sirva como parâmetro para avaliar os sistemas de ensino municipais e estaduais, a partir de resultados obtidos na Prova Brasil e dos dados de fluxo do Censo Escolar. Estados e municípios cujos desempenhos ficam aquém do estipulado pelo índice têm recebido apoio técnico e financeiro da União, desde que se comprometam formalmente com o cumprimento de metas estabelecidas. A principal delas é fazer com que os sistemas apresentem, até 2022, o ano do bicentenário da independência brasileira, performance semelhante à de países desenvolvidos.

Também no sentido de elevar a performance dos sistemas de ensino, em agosto de 2015, no primeiro ano do segundo mandato do governo Dilma Rousseff, o Ministro da Educação Renato Janine Ribeiro lançou uma nova plataforma intitulada Devolutivas Pedagógicas, destinada aos docentes e gestores escolares. Nela são apresentados e comentados pedagogicamente por especialistas itens que compõem a Prova Brasil, são oferecidas explicações sobre o método de elaboração dos itens e estão dispostas interpretações dos níveis de proficiência dos alunos em língua portuguesa e matemática. O intuito do MEC/INEP é o de explicitar aos educadores os conhecimentos e habilidades testados na prova, estimular a apropriação dos resultados do SAEB e "colaborar" com as atividades de ensino, mostrando aos docentes como é possível explorar tais resultados em sala de aula. Além disso, na plataforma, é possível comparar também os resultados da Prova Brasil entre escolas e diferentes localidades do país.

Faz-se necessário destacar ainda que, a partir de 2013, o SAEB passou por duas modificações importantes em sua estrutura: incluiu, em caráter experimental, a avaliação na área de Ciências para estudantes dos últimos anos do EF e do Ensino Médio (EM) e estabeleceu mais um instrumento de avaliação: a Avaliação Nacional da Alfabetização (ANA - cf. Portaria n $n^{482}$, de 07/06/2013), prevista no Pacto Nacional pela Alfabetização na Idade Certa (PNAIC - Portarian ${ }^{\circ} 867$, de 04/07/ 2012), que fixa os 8 anos de idade como o momento ideal para que todas as crianças estejam alfabetizadas, conforme meta prevista no Plano de Metas Compromisso Todos pela Educação.

De acordo com o INEP, a ANA é uma avaliação censitária, que ocorre anualmente junto aos alunos do $3^{\circ}$ ano do EF das escolas públicas, e tem por objetivo avaliar os níveis de alfabetização e letramento em Língua Portuguesa, a alfabetização Matemática e as condições de oferta do Ciclo de Alfabetização das redes públicas, dispondo, para tanto, de testes padronizados de desempenho e de questionários voltados aos professores e gestores das escolas.

Outra novidade que o INEP disponibilizou junto com os dados da edição de 2013 da ANA e da Prova Brasil foi a apresentação de dois indicadores contextuais - o Indicador de nível socioeconômico das escolas participantes (INSE) e o Indicador de formação docente -, além de um perfil de "Escolas Similares". Para compor o INSE utilizou como fontes os questionários contextuais de 2011 dos estudantes participantes do SAEB, da Prova Brasil e do ENEM. O índice sintetiza informações sobre escolaridade dos pais e renda familiar, com o objetivo de contextualizar o padrão de vida do público participante das avaliações conduzidas pelo INEP. Com isso, o órgão pretende ajudar a melhorar as análises e a compreensão sobre o desempenho das escolas, tendo em vista as próprias condições sociais e econômicas das instituições e dos municípios onde estão instaladas.

Já para a composição do Indicador de formação docente, a fonte utilizada foi o Censo Escolar da Educação Básica como objetivo de classificar os docentes pelo nível de adequação de sua formação inicial em relação à disciplina ministrada e à etapa de atuação na educação básica. No caso da ANA, o indicador mostra, em cada escola, o percentual de disciplinas de Língua Portuguesa e Matemática que são regidas por professores com Licenciatura em Pedagogia/Normal Superior, Licenciatura em Letras-Língua Portuguesa ou Matemática, respectivamente, ou por professores com Bacharelado em Pedagogia, Língua Portuguesa ou Matemática, que fizeram o devido curso de complementação pedagógica.

Por sua vez, o perfil de "Escolas Similares" sintetiza os resultados, por disciplina ou componente curricular no caso da ANA, de um grupo de escolas com características semelhantes em relação à sua localização por região no país, por ser considerada urbana ou rural e em relação aos valores próximos do INSE, permitindo, com isso, a análise contextualizada dos resultados obtidos. 
A estrutura dessas iniciativas remete ao juízo de que os contextos socioeconômicos e culturais contribuem decisivamente para a compreensão dos resultados das avaliações e que não apenas os alunos, mas as escolas, professores, diretores e os gestores dos sistemas de ensino são também responsáveis pelo desempenho dos estudantes e devem prestar contas à sociedade acerca dos resultados por eles obtidos. Com isso, o MEC reconhece a necessidade de aumentar a transparência nos serviços públicos e de adotar medidas de responsabilização, também chamadas de accountability.

Para produzir o impacto e atingir as metas estabelecidas para a educação básica, o governo federal tem estabelecido acordos que formalizam a adesão dos municípios em troca de sua assistência técnica e financeira - são ações como o aumento de recursos para o Programa Dinheiro Direto na Escola (PDDE) voltados às escolas que atingem as metas do MEC, a elaboração do Plano de Ações Articuladas (PAR), em conjunto com as administrações locais², a demarcação da área de atuação do Programa Mais Educação (escolas de educação integral), entre outras.

Apesar de tais medidas incorporarem avanços, como a responsabilização de todos os envolvidos no processo educacional pelos resultados obtidos; o estabelecimento de relações que têm formalmente como metaa garantia de apoio técnico e financeiro aos entes mais necessitados; a busca de resultados cada vez mais convergentes para os sistemas de ensino, estabelecendo metas diferenciadas em acordo com as possibilidades particulares e pretendendo, com isso, reduzir desigualdades regionais; nota-se que tais ações produzem concomitantemente uma série de "efeitos indesejáveis". A constante aplicação de testes padronizados tende a pressionar, enrijecer e induzir aredução da amplitude e variedade dos currículos escolares e a produzir, entre as escolas, estratégias que não propiciam elevação no nível de qualidade do processo educacional, mas encobrem os resultados por meio da omissão (ou mesmo exclusão) de alunos que apresentam baixa proficiência; deturpam informações sobre o fluxo escolar (repetência e evasão); fraudam o resultado dos testes, na medida em que professores respondem as questões junto com (ou pelos) alunos; ou mesmo pelo treino (e premiação) de estudantes para os exames.

Há que se reconhecer a coerência da atual política que procura estabelecer tanto a responsabilidade pública quanto a elevação dos padrões de desempenho dos sistemas de ensino. Entretanto, faz-se necessário problematizar os meios estabelecidos para atingir tais metas. Parece que os "danos colaterais" da aplicação de testes padronizados censitários nas escolas de EF indicam a necessidade de reavaliar essas ações, principalmente no sentido de separar a avaliação para a prestação de contas daquela feita para verificar os níveis de aprendizagem. Além disso, o foco estreito da Prova Brasil e do SAEB, desde o início, em Língua Portuguesa e Matemática, e mais recentemente em Ciências, assim como da ANA, não permite avaliar a amplitude curricular do EF. Melhor seria monitorar os sistemas de ensino por meio de testes amostrais mais amplos, que informassem sobre o desempenho dos estudantes em todas as áreas do conhecimento e, como complemento, poder-se-ia considerar a instituição de um sistema autônomo de supervisão das redes de ensino.

Não se pode negar que as características socioeconômicas dos alunos têm impacto mais significativo que os fatores intraescolares para explicar o desempenho escolar, fato evidenciado e reiteradamente comprovado desde a publicação do relatório Coleman (1966). As diferenças sociais que marcam os alunos brasileiros relativizam significativamente - se não, inviabilizam - a possibilidade de a escola cumprir seu papel de dar igual acesso a conhecimentos socialmente valorizados para toda a população estudantil. Óbvio está que as

20 PDDE foi criado em 1995, pelo MEC, para propiciar assistência financeira, em caráter suplementar, às escolas públicas de educação básica e às escolas privadas de educação especial, mantidas por entidades sem fins lucrativos. De acordo com o Ministério, o objetivo do programa é incentivar a melhoria da infraestrutura física e pedagógica das escolas e reforçar a autogestão escolar nos planos financeiro, administrativo e didático. Já o PAR, fruto do Plano de Desenvolvimento da Educação e da assinatura do plano de metas Compromisso Todos pela Educação, tem como objetivo incentivar a elaboração do planejamento da política de educação dos municípios, estados e DF por um período de quatro anos (2008 a 2011), auxiliando os entes na identificação das prioridades, tendo em vista as metas do Compromisso, eproporcionando recursos técnicos e financeiros. Para maiores informações dos programas vide o sítio do Fundo Nacional de Desenvolvimento da Educação (FNDE) - http://www.fnde.gov.br/. 
avaliações como o SAEB, a Prova Brasil e a ANA não modificam por si sós esta situação, determinada por relações sociais que extrapolam os muros da escola. No entanto, podem indicar características propriamente escolares que favoreçam a eficácia das instituições de ensino, a equidade dentro da escola, bem como a diminuição das desigualdades que ali se processam, mesmo que tais fatores tenham impacto relativamente pequeno no desempenho geral dos estudantes - nesse sentido, vide entre outros, estudos como os de Barboza e Fernandes (2001); Albernaz, Ferreira e Franco (2002); Soares (2003); Franco, Albernaz, Ortigão et al. (2007); Soares e Alves (2008).

Apesar de restritas no que toca à diminuição das diferenças sociais, as políticas educacionais deveriam mais que ampliar o monitoramento dos sistemas de ensino, tornando-os censitários, aprofundar o conhecimento acerca dos fatores que democratizam de fato o acesso aos conhecimentos e, então, ampliar o investimento onde comprovadamente haja impacto positivo para a qualidade do ensino nas escolas para todos os estudantes.

\section{Provinha Brasil}

No primeiro semestre de 2008, o MEC instituiu o primeiro ciclo da Provinha Brasil, um exame em larga escala destinado a crianças matriculadas no segundo ano do EF, geralmente com idades que variam entre seis e oito anos. A adesão ao exame é voluntária e o INEP, órgão responsável por sua organização, envia no início do ano às Secretarias de Educação duas versões da prova para que sejam aplicadas no começo e ao término do ano letivo.

De acordo com o Ministério, o objetivo dessa avaliação é "oferecer aos professores e gestores escolares um instrumento que permita acompanhar, avaliar e melhorar a qualidade da alfabetização e do letramento inicial oferecidos às crianças" (BRASIL, 2009a).

A partir dos resultados da prova realizada no início do ano, o MEC pretende que os professores tenham condições de verificar as habilidades e deficiências de seus alunos paraque venham a interferir positivamente no processo de alfabetização. Com os resultados da segunda prova, os professores passariam a ter condições de constatar a eficácia de suas ações ao longo do ano e de refletir sobre os processos de ensino.

A Provinha Brasil é composta de 24 questões de múltipla escolha e três questões escritas, elaboradas a partir de uma matriz de referência para a avaliação da alfabetização e do letramento inicial, feita pelo MEC. A prova deve ser aplicada em horário de aula pelo professor da turma, ou por outro aplicador, e os resultados devem ser processados a partir de um guia que orienta a correção e a interpretação dos dados. Com isso, o MEC pretende que o professor saiba o nível de desempenho de sua turma de modo imediato.

Além disso, para dar visibilidade, deixar acessível e fomentar o tipo de interpretação de resultados que recomenda, o INEP lançou em 2014 uma plataforma online chamada Sistema Provinha Brasil. Para escolas e sistemas de ensino que optarem pela utilização da plataforma, os diretores escolares devem cadastrar docentesaplicadores do teste, turmas e alunos e, posteriormente, os professores devem lançar os resultados de sua turma, para então serem gerados relatórios de desempenho por aluno, turma e item de prova e respectivas análises de resultados.

No relatório por aluno, pode-se verificar o número de acertos e o nível de desempenho geral na prova e, também, por item da prova, junto com a descrição das habilidades mensuradas em cada item. No relatório por turma, pode-se verificar o desempenho geral de cada turma, pela distribuição dos níveis de desempenho dos alunos e também pelo acompanhamento da "evolução" por nível de desempenho de turmas, alunos e escola, na comparação entre as provas aplicadas no primeiro e no segundo semestres do ano. No relatório por item de prova, pode-se analisar os erros dos alunos, em acordo com os critérios e padrões estabelecidos pelo INEP, bem como verificar quais foram as respostas em cada alternativa nas questões da Provinha Brasil.

Além de estimular docentes e gestores dos sistemas de ensino a uma visão padronizada do desempenho das crianças de cerca de sete anos de idade, negando com isso a existência de trajetórias singulares de 
aprendizagem, de diferentes interpretações na leitura e, portanto, de múltiplas possibilidades de respostas a uma mesma questão, esses procedimentos introduzem os exames em larga escala logo no início da escolarização e inserem, desde muito cedo, as crianças em experiências atípicas, já que até então as avaliações padronizadas que pretendem aferir os resultados do processo de letramento não possuem relação alguma com os processos vividos cotidianamente nas escolas. De acordo com Esteban (2009), foram os resultados insatisfatórios do SAEB para o primeiro ciclo do EF que constituíram "o argumento para a ampliação do sistema de avaliação, levando-o a abarcar as crianças em início de escolarização" (p.50).

Evidências contidas em relatório inglês, intitulado The Cambridge Primary Review Research Surveys (ALEXANDER et al, 2009), iluminam este debate mostrando os sérios problemas subjacentes à intervenção e ao controle do Estado Inglês sobre a infância. Os resultados desse survey, produzido por professores de Cambridge que procuraram atualizar o tipo de análise de política educacional inaugurada pelo Relatório Plowden (1967), trazem indicações como as de reconsiderar a idade para o início da escolaridade obrigatória; de rever a influência externa sobre o currículo nos primeiros anos de escolarização, que tem sido limitado pela pressão subjacente à preparação dos alunos para os testes em larga escala; de rever a intervenção governamental que requer das escolas concentrarem-se no "básico", excluindo muita coisa essencial que não tem sido considerada importante; de abolir os testes externos por produzirem estresse nas crianças e por comprometerem a qualidade da educação elementar.

Ao mesmo tempo, o Relatório deixa claro o apoio às aspirações e à agenda da política inglesa denominada "Every Child Matters" (Toda a Criança tem Importância), julgando necessária a intervenção pública em casos de crianças e famílias vulneráveis. Mesmo assim, são levantadas dúvidas sobre a extensão e a natureza dessa intervenção.

Ao que parece, tal como ocorre na Inglaterra, a Provinha Brasil configura-se como mais um instrumento de elevação do controle externo sobre as escolas e as práticas docentes, deixando de incidir, no entanto, nos complexos fatores que determinam o fracasso escolar de grande parte da jovem população estudantil.

\section{ENEM}

A primeira edição do Exame Nacional do Ensino Médio (ENEM) ocorreu em 1998 e a iniciativa foi caracterizada pelo governo federal como inovadora por seu caráter interdisciplinar e a ênfase na avaliação de competências e habilidades. Desde então, o exame tem sido realizado anualmente, junto aos concluintes ou egressos do EM. Inicialmente, apresentou os seguintes objetivos: avaliar o desempenho do aluno ao término da escolaridade básica; aferir o desenvolvimento de competências fundamentais ao exercício pleno da cidadania; oferecer uma referência de auto-avaliação aos jovens, tanto em relação ao mercado de trabalho quanto em relação à continuidade de estudos; servir como modalidade alternativa ou complementar aos processos de seleção nos diferentes setores do mundo do trabalho, bem como de cursos profissionalizantes pós-médios e do ensino superior.

Por 11 anos consecutivos, o ENEM teve a mesma estrutura: foi constituído por uma única prova que abrangia as várias áreas de conhecimento, estruturada com 63 questões de múltipla escolha e uma redação dissertativa/ argumentativa, acerca de temas de ordem social, cultural ou política. Desde o início, o exame funcionou como instrumento complementar ou alternativo aos processos seletivos para o nível superior, tanto em instituições públicas como privadas, o que lhe conferiu posição de destaque no EM, visto o aumento significativo no número de participantes do ENEM ao longo do tempo. Em 2005, o ENEM passou a ser utilizado também como critério de seleção de bolsistas no ensino superior pelo Programa Universidade para Todos (ProUni), fato que impactou significativamente o número de participantes no exame: em 2004, foram cerca de 1,5 milhões de inscritos e, em 2005, o número dobrou para cerca de 3 milhões. Em 2010, passou a ser uma das principais formas de acesso ao ensino superior público, tendo contado, em 2014, com mais de 8,7 milhões participantes. 
No ano de 2009, o MEC formalizou uma proposta de reestruturação metodológica do ENEM à Associação Nacional de Dirigentes das Instituições Federais de Educação Superior (Andifes) e ao Conselho Nacional de Secretários de Educação (Consed) para que fosse utilizado por todas as Instituições Federais de Educação Superior (IFES) como subsídio aos seus processos seletivos de ingresso, argumentando positivamente sobre os "ganhos de um processo unificado de seleção e a possibilidade concreta de [...] reestruturação de currículos no ensino médio" (BRASIL, 2009b, p. 1). De acordo com a proposta, a adesão das diversas IFES a um sistema unificado de seleção permitiria ampliar as oportunidades de acesso aos jovens brasileiros às respectivas vagas, além de estimular a mobilidade dos estudantes entre as diferentes regiões do país e propiciar uma relação positiva entre o EM e o ensino superior (ES), com a discussão e o estabelecimento de novas diretrizes para a prova. Neste último sentido, o MEC indicou as diretrizes do Exame Nacional para Certificação de Competências de Jovens e Adultos (ENCCEJA) para fundamentar a nova matriz do ENEM. O exame seria subdividido em quatro testes compostos por aproximadamente 50 itens de múltipla escolha, além de uma redação, em uma configuração que permitiria ter boa precisão na aferição das proficiências ${ }^{3}$.

As IFES tiveram autonomia para optar entre quatro possibilidades de utilização do Novo ENEM em seus processos seletivos: como fase única; como primeira fase; combinado o exame com o vestibular da instituição; e como fase única para as vagas remanescentes do vestibular. Além da redação, o formato final do Novo ENEM ficou em 180 questões objetivas, divididas nas quatro áreas do conhecimento da matriz do ENCCEJA: Linguagens, códigos e suas tecnologias; Ciências humanas e suas tecnologias; Ciências da natureza e suas tecnologias e Matemáticas e suas tecnologias, cada uma delas com 45 itens de múltipla escolha.

Com essa medida, o MEC ampliou os objetivos do ENEM, definindo metas bem pretensiosas: democratizar as oportunidades de acesso às vagas federais de ES e pós-médio; induzir a reestruturação dos currículos do EM; possibilitar a mobilidade acadêmica dos estudantes pelo país; promover avaliação do desempenho acadêmico dos ingressantes nas IES; promover certificação de jovens e adultos no nível de conclusão do EM e possibilitar sua participação em programas governamentais.

No que se refere ao primeiro objetivo, não parece haver evidências suficientes que permitam considerar as mudanças do Novo ENEM como uma medida eficiente para alterar de forma significativa o perfil dos ingressantes nas instituições e cursos superiores de grande atratividade e, por isso mesmo, muito seletivos. Entre as variáveis que sabidamente têm impacto na definição dos ingressantes no ES destaca-se o nível socioeconômico dos estudantes e, neste país, já foi comprovada a forte associação entre a escolarização básica de boa qualidade e o nível socioeconômico dos alunos. Esse fato mostra que a simples reformulação do instrumento de avaliação, tal como se configurou a proposta do governo federal, não é capaz de produzir impacto suficiente para modificar a realidade brasileira, já que nem incide sobre as condições objetivas de escolarização dos estudantes, nem tampouco sobre seu nível socioeconômico. Essa tarefa tem sido alcançada muito mais pela expansão do número de vagas públicas, pelo cumprimento da Lei $n^{\circ}$ 12.711/2012, que estabelece cotas sociais para o ingresso nas IFES, e pelo Plano Nacional de Assistência Estudantil (PNAES, Portaria Normativa $n^{\circ} 39$, de 2007), que financia a permanência dos estudantesmais carentes nas instituições federais.

No entanto, a posição de destaque do Novo ENEM como principal instrumento da seleção unificada para o ingresso em instituições públicas de ensino superior parece permitir considerar efetiva a indução de mudanças no currículo do EM (MINHOTO, 2009).De acordo com pesquisas produzidas recentemente que tratam direta ou indiretamente sobre os impactos do ENEM nessa etapa da escolarização básica (BERGAMIN, 2013; SOUZA, 2014; TRAVITZKI, 2013), é possível afirmar que o exame vem exercendo interferência no trabalho do professor, no que toca ao planejamento das aulas e à adoção de instrumentos didático-metodológicos afinados com sua matriz de habilidades e competências, e

3 A íntegra do documento enviado à Andifes e ao Consed pelo MEC pode ser acessada em: http://portal.mec.gov.br/index.php?option=com docman\&task=doc_download\&gid=768\&ltemid (Acesso em 28/10/2013). 
contribuído para o estabelecimento de uma característica mais propedêutica ao EM em detrimento de uma formação voltada eminentemente ao exercício da cidadania e à preservação de conhecimentos socialmente valorizados, como deveria ocorrer com a etapa final da escolarização básica, de acordo com a CF/88 e a LDB/96.

A matriz e os conteúdos do novo ENEM, definidos com participação da Andifes e do Consed, teve como marca principal a aproximação da forma e do conteúdo do exame aos antigos e concorridos vestibulares, uma mudança profunda em relação aos princípios que guiavam a elaboração do exame em suas 11 primeiras edições e que respondeu fundamentalmente ao objetivo de selecionar indivíduos ao ES público, ou "candidatos extremamente preparados", a partir de "itens de alta complexidade, capazes de discriminar alunos de altíssima proficiência daqueles de alta proficiência" (BRASIL, 2009b, p. 5). Por fim, a determinação desse "novo" formato, com a apresentação dos conteúdos em textos extensos e tipicamente acadêmicos, revela a aproximação do ENEM às necessidades de seleção para o ingresso no competitivo mundo do ES público brasileiro, deixando claro seu principal caráter atualmente.

Ainda no que toca à função de acesso ao ES, é preciso destacar que o exame tem sido usado também fora das fronteiras nacionais. As Universidades portuguesas de Coimbra (UC), Algarve (UAlg) e Beira Interior (UBI) anunciaram a adesão ao ENEM para ingresso de estudantes brasileiros em seus cursos de graduação, no ano de 2014, o que parece legitimar socialmente e consolidar ainda mais o exame como instrumento de seleção ao ES.

Sobre o objetivo de estimular a mobilidade dos estudantes em território nacional, destaca-se a inegável comodidade e eficiência econômica da plataforma instituída pelo MEC, chamada de Sistema de Seleção Unificada (SiSU), tendo em vista que beneficia tanto os candidatos ao ES quanto as próprias instituições, oferecendo, por um lado, milhares de vagas de forma unificada em distintas instituições, concomitantemente ao acesso ao exame em território nacional para os interessados e, por outro, a redução de custos para todos os envolvidos nos processos seletivos. Tendo como base a lógica da eficiência econômica na ocupação das vagas, com a divulgação dos resultados do ENEM o sistema permite aos candidatos que antevejam as possibilidades concretas de ingresso em diferentes cursos e disponibiliza inúmeras alternativas àqueles que não obtiveram nota suficiente para concretizar a sua escolha. Com isso, muitos jovens são estimulados a substituir seus interesses iniciais pela mera viabilidade do ingresso em graduações de menor ou nenhum interesse, o que além de promover escolhas irracionais gera muita evasão entre as IFES, que acabam sendo apontadas como responsáveis por uma ineficiência que na verdade não Ihes pertence, mas é proveniente da própria lógica do sistema.

Finalmente, vale destacar mais uma utilização do ENEM, a partir de 2010, com a possibilidade de declaração de proficiência e de certificação no EM (cf. Portaria normativa n. 4 de 11/02/2010). Em fevereiro de 2010, ficou definido que os procedimentos para a certificação parcial de proficiência e para a certificação no EM com base nas notas do exame seriam de competência das Secretarias de Educação e dos Institutos Federais de Educação, Ciência e Tecnologia. Para obter a certificação, nos anos de 2010 e 2011, os interessados deveriam obter pontuação mínima de 400 pontos em cada prova objetiva do ENEM e de 500 na redação e, a partir de 2012, a pontuação mínima nas provas objetivas subiu para 450 pontos, permanecendo a mesma nota para a redação (Portaria n 144, de 24 de maio de 2012).

Ao solicitante, ficou também facultada a possibilidade de utilizar os resultados de edições anteriores do ENEM (a partir de 2009) e do ENCCEJA-Ensino Médio (até 2008) para obter o certificado do EM, bem como de aproveitar as declarações parciais de proficiência obtidas em todas as edições do ENCCEJA-Ensino Médio realizadas no exterior. De acordo com o INEP, a correspondência entre os resultados obtidos dessas diversas aplicações provêm de dois pressupostos:

1) relativamente às concepções pedagógicas desses Exames, a matriz de referência do ENEM foi concebida a partir da matriz do ENCCEJA e ambas guardam ainda um forte parentesco entre temas, competências e habilidades nas diferentes áreas de conhecimento; 2) os pontos de certificação, mesmo expressos em escalas distintas, são equivalentes e, desta forma, as pontuações mantêm fortes níveis de correspondência (BRASIL, 2014, p. 6). 
Entretanto, como destacado anteriormente, o ENEM foi revisto e modificado para atender às demandas de seleção de candidatos para o competitivo ES público brasileiro e para induzir mudanças nos currículos do EM, o que difere de seus objetivos iniciais de avaliar o desempenho de estudantes ao término da escolaridade básica e de aferir o desenvolvimento de competências fundamentais ao exercício pleno da cidadania. Para os que buscam a certificação no EM via ENEM, essa mudança pouco contribui à obtenção das pontuações mínimas necessárias, visto que para boa parte dos interessados não foi garantido o direito de frequentar regularmente o EM ou mesmo outras etapas da educação básica. Como remédio para o descumprimento da obrigação legal de oferecer educação básica regular a todo o cidadão brasileiro, o estado apresenta como alternativa um procedimento que acaba por responsabilizar o próprio indivíduo espoliado de seus direitos a comprovar conhecimentos que a ele não foi dada a justa oportunidade de aprender.

\section{ENCCEJA}

O Exame Nacional de Certificação de Competência de Jovens e Adultos (ENCCEJA) foi criado em 2002 para, de acordo com o MEC, aferir as competências e habilidades dessa população, nos níveis de conclusão do EF e EM, tendo por objetivos: construir uma referência nacional de auto-avaliação, adquiridas no processo escolar ou nos processos formativos que se desenvolvem na vida familiar, na convivência humana, no trabalho, nos movimentos sociais e organizações da sociedade civil e nas manifestações culturais; e servir às Secretarias de Educação como instrumento de aferição de conhecimentos e habilidades dos participantes nos níveis de conclusão do EF e EM.

O ENCCEJA não se propõe a avaliar a educação, as escolas ou os procedimentos de ensino, mas validar e certificar os conhecimentos, competências e habilidades dos participantes do exame, individualmente, como conhecimentos escolares. As provas estão estruturadas em quatro áreas de conhecimento, tanto no EF como no EM, tal como ocorre no ENEM. Até 2009, o ENCCEJA certificou ambas as etapas de ensino, porém, com a instituição do novo ENEM passou a certificar apenas o EF, visto que para a certificação no EM os brasileiros passaram a dispor do ENEM para tal função. No Exterior, além do EF, os interessados podem pleitear a certificação no nível de conclusão do EM, desde que tenham no mínimo 18 anos completos na data de realização das provas.

O participante deve obter, na parte objetiva da prova em cada uma das áreas, o nível 100 (cem), no mínimo, em uma escala de proficiência que varia entre 60 e 180. Esse nível de proficiência significa que o participante desenvolveu as habilidades mínimas necessárias para obter a certificação.

A adesão ao exame é opcional e, até 2008, tanto as Secretarias Municipais como as Estaduais de Educação poderiam efetivá-la mediante a assinatura de um termo de parceria específico com o INEP, órgão do MEC que elabora as provas e os materiais de orientação, além de prestar assistência técnica em todo o processo, corrigindo as provas e analisando os resultados. A partir de 2010, a adesão ficou disponível somente às Secretarias Estaduais de Educação, assim sendo, são atualmenteos órgãos responsáveis pela adesão ao ENCCEJA e definem tanto os critérios de utilização do exame para fins de certificação, como as inscrições, o cadastro dos inscritos, a aplicação das provas, a divulgação dos resultados e o envio das informações ao INEP. Além disso, desde 2010, o INEP passou a publicar edital específico para a realização do ENCCEJA aos adultos submetidos a penas privativas de liberdade e adolescentes sob medidas socioeducativas que incluam privação de liberdade.

Apesar de o exame ter sido instituído em 2002, ele não se realizou nos anos seguintes (2003 e 2004), por conta de pressões contrárias de vários segmentos que atuam na EJA e que advogam a necessidade de realização de um amplo debate sobre o tema. Entretanto, a partir de 2005, o exame foi reeditado pelo MEC. Os argumentos contrários à realização do exame foram desde a problematização da padronização e abrangência nacional do ENCCEJA, que pressupõem uma visão sistêmica da EJA, incompatível com a própria história de 
escolarização da referida população e a valorização de seus conhecimentos e saberes adquiridos ao longo da vida, até a fragmentação das disciplinas, com a certificação parcelada, que milita contra os fundamentos das reformas de ensino, quais sejam: o dacontextualização e da interdisciplinaridade dos conhecimentos, não se prestando, portanto, a avaliar os indivíduos, seus saberes e experiências acumulados.

O tema da certificação de jovens e adultos que deixam de concluir a educação básica em tempo ideal não pode prescindir do debate acerca da histórica falta de estrutura da política de atendimento educacional dessa população. Em especial, é preciso atentar para os impactos negativos do exame no que se refere ao direito à educação, ou ao dever do Estado e das famílias em oferecer educação básica. A baixa idade com que a população pode participar dos processos de certificação, atualmente - para o EF, 15 anos, e para o EM, 18 anos, via ENEM - parece propiciar o descompromisso do Estado em oferecer educação, mesmo estando a população em idade escolar. Como é possível observar, o ENCCEJA e o ENEM abrem aos jovens um atalho que suprime a trajetória completa da educação básica.

Se por um lado, a política de avaliação destinada aos jovens e adultos permite constatar que a forma de organização da sociedade contemporânea não promove, para todos, oportunidades iguais para o desenvolvimento de suas habilidades, bem como de condições similares para o ingresso no mercado de trabalho, por outro, ilumina a crescente importância da educação em suas vidas. Quanto mais longe o indivíduo avança no sistema de ensino - em uma trajetória definida e entremeada por diferentes avaliações - maior é sua possibilidade de inserção social de destaque.

A explicação mais frequente para essas constatações é a de que vivemos em uma "sociedade do conhecimento" e a educação é a variável mais importante para definir a estratificação e a mobilidade social. Qualquer ocupação social depende atualmente cada vez mais de avanços científicos e de novas formas de tecnologia e, nesse sentido, a garantia de uma boa colocação relaciona-se cada vez mais com a produção e a aquisição de novos conhecimentos. De acordo com a lógica dessa explicação, a sociedade moderna deixa para trás um sistema de provimento ocupacional calcado em privilégios para estabelecer um sistema hierárquico pautado no desenvolvimento de méritos técnicos. Daí, a importância do sistema educacional e de sua qualidade, verificados e controlados pelas avaliações.

Ainda que se possa compreender a argumentação favorável à criação de alternativas ao processo de escolarização regular para um público que deseja retomar a própria trajetória educacional, ingressando no ensino superior ou técnico, ou mesmo para ascender profissionalmente, o ENCCEJA (e, em certa medida, o ENEM) parece valorizar menos as condições de acesso aos conhecimentos socialmente valorizados por jovens e adultos e mais a aquisição de uma certificação, ao reforçar sua importância.Para os que não tiveram o direito à educação básica assegurado pelo Estado o exame parece endossar a lógica de garantir o mínimo para responder a um futuro de adaptação à ordem social hierarquizada vigente, em que não há o menor espaço para questionamentos ou transformação.

\section{Considerações Finais}

Para finalizar, tendo em vista o panorama geral apresentado, apontam-se aqui considerações a respeito de alguns pontos de tensão que vêm marcandoo Sistema Nacional de Avaliação (SNA) no que diz respeito à Educação Básica. Em termos operacionais, nota-se que o SNA passou a ser composto por um número crescente de avaliações em larga escala, no período. São processos uniformizados, centralizados e quantitativos, acompanhados de iniciativas recentes e mais pronunciadas que estimulam o uso dos resultados obtidos, buscando induzir mudanças no trabalho do professor e no cotidiano das instituições de ensino - tal como as plataformas Devolutivas Pedagógicas e Sistema Provinha Brasil -, o que tendencialmente produz a imobilidade e a padronizaçãodos sistemas educacionais. 
Tal característica choca-se com as prescrições contidas na $\mathrm{CF} / 88$, no que se refere à gestão das relações entre os sistemas de ensino. Em termos de gestão, sobressai como princípio constitucional o regime de colaboração entre os entes federados, o que deveria garantir e fomentar a realização de processos multiformes, descentralizados, cooperados, qualitativos e autônomos de avaliação.

Além disso, vários aspectos do SNAevidenciam o seu potencial ideológico, na medida em que, por exemplo, pretende avaliar a qualidade do ensino por meio da operação redutora que identifica qualidade imediatamente com desempenho dos alunos; ou, quando o resultado do levantamento de informações, feito por meio dos questionários contextuais, acaba compondo o núcleo principal da argumentação dos governos para qualificar como satisfatórias as condições físicas e humanas das escolas públicas, enquanto, na verdade, uma breve incursão na empiria mostra que as condições são na maioria dos casos apenas sofríveis; ou ainda, quando os resultados educacionais são usados pela mídia e pelos órgãos oficiais como informações objetivas e naturais, ocultando sua face parcial, na medida em que expressam tão somente uma faceta da realidade, fazendo com que tomemos a parte pelo todo, fomentando a distorção e não o esclarecimento.

Se estimulasse e produzisse estudos de maior complexidade sobre a qualidade da educação nacional, como uma política consistente e perene, o Estado revelaria maior disposição para compreender a radicalidade dos problemas e as contradições da realidade educacional brasileira, condição essencial para promover uma educação popular de qualidade. Usados como ferramentas de esclarecimento, os indicadores educacionais poderiam auxiliar no enfrentamento do que é verdadeiramente exasperador na educação do país: a perpetuação da extrema desigualdade ao acesso e à fruição da cultura e dos conhecimentos socialmente referenciados. Sem dúvida, a avaliação rigorosa da qualidade das escolas e dos sistemas educacionais é elemento imprescindível para a construção de uma sociedade justa e democrática e é por esse motivo que deve estar sempre submetida ao crivo da crítica.

Entretanto, fica claro que no âmbito do SNA ainda é preciso haver muito mais espaço para que os problemas educacionais sejam entendidos por todos à luz das contradições sociais. O que tem sido disseminado é a certeza de que tais problemas são desvios ou incorreções de funcionamento do próprio sistema de educação brasileiro, convertidos, portanto, em problemas técnicos, de gestão. Parece que o tratamento crescentemente sistemático e técnico dos problemas educacionais e as consequências que produz em termos de ações políticas, além de não avançar positivamente em direção a mais qualidade em educação, tende a reforçar a visão tecnológica da realidade.

\section{Referências}

ALBERNAZ, A.; FERREIRA, F.; FRANCO, C. Qualidade e equidade no ensino fundamental brasileiro. Pesquisa e Planejamento Econômico. Rio de Janeiro, v. 32, n. 3. 2002.

ALEXANDER, R.; DODDINGTON, C.; GRAY, J.; HARGREAVES, L.; KERSHNER, R. The Cambridge Primary Review Research Surveys. England: Routledge. 2009.

BARBOSA, M. E. F. e FERNANDES, C. A escola brasileira faz diferença? Uma investigação dos efeitos da escola na proficiência em Matemática dos alunos da 4a série. In: FRANCO, C. Promoção, ciclos e avaliação educacional. Porto Alegre: Artmed, p. 155-172. 2001.

BERGAMIN, F. M. B. Currículo e Exame Nacional do Ensino Médio: rupturas e permanências na conformação dos saberes históricos escolares. Dissertação de mestrado em Educação, Pontifícia Universidade Católica de São Paulo (PUC-SP), 2013.

BESSON, J. L. A llusão das Estatísticas. Tradução de Emir Sader. São Paulo: UNESP. 1995.

BONAMINO, A.; FRANCO, C. Avaliação e Política Educacional: o processo de instituição do SAEB. Cadernos de Pesquisa. São Paulo: n. 108, p. 101-132, nov. 1999. 
BRASIL. Guia de certificação 2014. Disponível em: http://download.INEP.gov.br/educacao_basica/enem/ certificacao/2014/guia_certificacao_enem_2014.pdf, acesso em: 02/09/2015.

BRASIL. Provinha Brasil - Apresentação. Disponível no site do MEC, em 22/09/2009: http://portal.mec.gov.br/ index.php?option=com_content\&view=article\&id=211\&ltemid=86. 2009a.

BRASIL. Proposta à Associação Nacional dos Dirigentes das Instituições Federais de Ensino Superior. Brasília, 2009b.

BRASIL. Lei $n^{\circ} 12.711$, de 29 de agosto de 2012. Lei de Cotas: dispõe sobre o ingresso nas universidades federais e nas instituições federais de ensino técnico de nível médio.

BRASIL. Portaria Normativa $n^{\circ} 39$, de 12 de Dezembro de 2007. Institui o Programa Nacional de Assistência Estudantil - PNAES. Brasília.

ESTEBAN, M. T. Provinha Brasil: desempenho escolar e discursos normativos sobre a infância. Sísifo: Revista de Ciências da Educação. N. ${ }^{\circ}$ 9, mai/ago. 2009.

FERNANDES, R.; GREMAUD, A. Qualidade da Educação: avaliação, indicadores e metas. Disponível em: http://www3.fgv.br/ibrecps/rede/seminario/reynaldo_paper.pdf. 2009.

FRANCO, C.; ORTIGÃO, M. I.; ALBERNAZ, A.; BONAMINO, A.; AGUIAR, G.; ALVES, F.; SATYRO, N. Qualidade e equidade em educação: reconsiderando o significado de fatores intra-escolares. Ensaio: avaliação e políticas públicas educacionais. Rio de Janeiro, v.15, n.55, p. 277-298, abr.jun. 2007.

MINHOTO, M. A. P. Modelação Curricular do Ensino Médio: análise de prescrições legais e do papel da avaliação dos sistemas de ensino. Jornal de Políticas Educacionais, v. n. 5, p. 27-36. 2009.

SOARES, J. F. e ALVES, M.T. G. O efeito das escolas no aprendizado dos alunos: um estudo com dados longitudinais no Ensino Fundamental. Educação e Pesquisa. São Paulo, v.34, n.3, p. 527-544, set./dez. 2008.

SOARES, T. M. Influência do professor e do ambiente em sala de aula sobre a proficiência alcançada pelos alunos avaliados no Simave 2002. Estudos em Avaliação Educacional. São Paulo, v. 28, p. 103-123. 2003.

SOUZA, D. L. Os Usos e Objetivos do Enem na Avaliação de Jovens e Educadores da Rede de Ensino de Guarulhos. Trabalho de Conclusão de Curso - Departamento de Educação da Escola de Filosofia Letras e Ciências Humanas da Unifesp, Guarulhos, 2014.

TRAVITZKI, R. ENEM: limites e possibilidades do Exame Nacional do Ensino Médio enquanto indicador de qualidade escolar. 2013. Tese de Doutorado - Faculdade de Educação, Universidade de São Paulo, São Paulo, 2013.

Recebido em Outubro de 2015 | Aprovado em Fevereiro de 2016. 